\title{
Identification of putative TAL effector targets of the citrus canker pathogens shows functional convergence underlying disease development and defense response
}

Andre LA Pereira ${ }^{1+}$, Marcelo F Carazzolle $e^{1,2+}$, Valeria Y Abe ${ }^{1}$, Maria LP de Oliveira ${ }^{1,3}$, Mariane N Domingues ${ }^{1}$, Jaqueline C Silva ${ }^{1}$, Raul A Cernadas ${ }^{1,4}$ and Celso E Benedetti ${ }^{1 *}$

\begin{abstract}
Background: Transcriptional activator-like (TAL) effectors, formerly known as the AvrBs3/PthA protein family, are DNA-binding effectors broadly found in Xanthomonas spp. that transactivate host genes upon injection via the bacterial type three-secretion system. Biologically relevant targets of TAL effectors, i.e. host genes whose induction is vital to establish a compatible interaction, have been reported for xanthomonads that colonize rice and pepper; however, citrus genes modulated by the TAL effectors PthA"s" and PthC"s" of the citrus canker bacteria Xanthomonas citri $\left(X_{c}\right)$ and Xanthomonas aurantifolii pathotype $C\left(X_{a C}\right)$, respectively, are poorly characterized. Of particular interest, $\mathrm{XaC}$ causes canker disease in its host lemon (Citrus aurantifolia), but triggers a defense response in sweet orange.
\end{abstract}

Results: Based on, 1) the TAL effector-DNA binding code, 2) gene expression data of Xc and XaC-infiltrated sweet orange leaves, and 3) citrus hypocotyls transformed with PthA2, PthA4 or PthC1, we have identified a collection of Citrus sinensis genes potentially targeted by $X_{c}$ and $X_{a C}$ TAL effectors. Our results suggest that similar with other strains of Xanthomonas TAL effectors, PthA2 and PthA4, and PthC1 to some extent, functionally converge. In particular, towards induction of genes involved in the auxin and gibberellin synthesis and response, cell division, and defense response. We also present evidence indicating that the TAL effectors act as transcriptional repressors and that the best scoring predicted DNA targets of PthA "s" and PthC"s" in citrus promoters predominantly overlap with or localize near to TATA boxes of core promoters, supporting the idea that TAL effectors interact with the host basal transcriptional machinery to recruit the RNA pol II and start transcription.

Conclusions: The identification of PthA"s" and PthC"s" targets, such as the LOB (LATERAL ORGAN BOUNDARY) and CCNBS genes that we report here, is key for the understanding of the canker symptoms development during host susceptibility, or the defenses of sweet orange against the canker bacteria. We have narrowed down candidate targets to a few, which pointed out the host metabolic pathways explored by the pathogens.

Keywords: TAL effectors, PthA, PthC, Xanthomonas citri, Xanthomonas aurantifolii, Citrus canker, Target genes

\footnotetext{
* Correspondence: celso.benedetti@Inbio.cnpem.br

${ }^{\dagger}$ Equal contributors

'Laboratório Nacional de Biociências, Centro Nacional de Pesquisa em Energia e Materiais, R. Giuseppe Máximo Scolfaro 10000, Campinas, SP 13083-970, Brazil

Full list of author information is available at the end of the article
} 


\section{Background}

Transcriptional activator-like (TAL) effectors of Xanthomonas spp. had been featured as central determinants of both bacterial pathogenicity and avirulence in numerous plant species or cultivars [1-6]. However, it was not until recently that the biochemical function of TAL effectors as transcriptional regulators was discovered [6-13].

The tridimensional structure of TAL effectors showed that these proteins are distinct from any other bacterial effectors that are targeted to the interior of the host cell by the type-III secretion system [14-17]. TAL effectors striking signature is made by the polymorphisms in positions $12-13^{\text {th }}$ of the $33-34$ amino acids tandem repeats, referred as repeat-variable diresidues (RVDs), which comprise the DNA-binding domain of the effector [12,13]. The consecutive repeats wrap around the DNA double helix, accommodating the RVDs adjacent to the target DNA bases in a one-to-one RVD-DNA base fashion, which are stabilized by hydrogen bonds and/or Wan-der Waals forces between the $13^{\text {th }}$ RVD residue and the DNA base [15-17]. These TAL effector-targeted sequences have been initially called UPT (up-regulated by TAL effector) boxes, and later more broadly, Effector Binding Elements (EBEs) $[6,9]$. The discovery of the TAL effector code has provided an invaluable tool for genome engineering by user-designed TAL effectors fused to catalytic domains, or designer TAL effectors to activate gene expression and explore their function during bacterial infection processes [18-20].

Based on host-range, Xanthomonas citri strains belong into different pathotypes being the Asian group A the most aggressive that exhibit wide-host range. Strains from groups $\mathrm{B}$ and $\mathrm{C}$ form a phylogenetically distinct clade originated in South America that exhibit limited host range [4,21]. The TAL effectors identified in $X$. citri strains were designated PthA"s", PthB"s" and PthC"s", and despite they are inherent in pathogenicity, the corresponding host gene targets remain uncharacterized [2,4,21-23]. Interestingly, a pioneering study showed that pathotypes A, B and $\mathrm{C}$ carry at least one isofunctional PthA, PthB or PthC effector of 17.5 repeat domains, which is essentially required to elicit hyperplastic canker lesions on citrus [4,21]. On the other hand, none of the TAL effectors from the limited-host-range strains (pathotypes $\mathrm{B}$ and $\mathrm{C}$ ) was able to trigger the hypersensitive response (HR) observed in grapefruit plants when expressed heterologously in other strain, suggesting that TAL effectors from citrus canker pathogens do not limit host range but rather contribute to virulence associated functions [4,21].

Recent reports have focused on the computationalbased prediction of EBEs in plant genomes to identify the putative host gene targets of TAL effectors [13,24,25]. For citrus, the in silico analyses to predict PthA"s" targets in sweet orange provided a set of candidates but additional experimental evidence of, e.g. gene expression, is still needed to validate such predictions [24]. Also, those studies did not include PthB"s" or PthC"s" effectors from the restricted host-range strains like Xanthomonas aurantifolii pathotype $\mathrm{C}(\mathrm{XaC})$, which in turn trigger a defense response in sweet oranges. Such analyses could provide molecular candidates that regulate the citrus defense response against Xanthomonas spp. [24,26]. In other pathosystems, the identification of TAL effectorinduced genes of $X$. vesicatoria and $X$. oryzae has revealed novel virulence mechanisms of plant bacteria mediated by the targeted transcriptional induction of key regulators of host susceptibility $[3,6,8,11]$. Therefore, identification of TAL effector targeted factors that regulate citrus canker susceptibility is a milestone to understand and improve disease resistance.

Using microarray analyses, we have previously shown that the genes up-regulated by $\mathrm{XaC}$ in sweet orange leaves are involved in basal defense. In contrast, $X$. citri $\left(\mathrm{Xc}_{\mathrm{C}}\right)$ induced genes associated with cell division and growth at the beginning of the infection process [26]. We also found that many of the rapidly Xc-induced genes, including cellulases, expansins and other cell-wall remodeling proteins, are co-regulated by auxin and gibberellin, hormones that are required for canker development [27] and control cell growth and expansion in other plant species [28]. TAL effectors not only play a central role as major determinants of host susceptibility, but are also capable of eliciting a resistance response when targeting HR-executor genes $[3,6-8,29,30]$. Based on these evidences, we hypothesized that TAL effectors from $\mathrm{Xc}$ and $\mathrm{XaC}$ are directly regulating the transcription of sweet orange genes involved in canker formation and defense response, respectively.

In this study, we present a combination of bioinformatics, microarray analyses, and molecular assays to identify sweet orange genes targeted by PthA2, PthA4 and PthC1 proteins. We show that the ectopic expression of PthA2, PthA4 or PthC1 in citrus epicotyls resulted in the upregulation of a group of genes involved in auxin and gibberellin response, cell growth, and defense response. Our in silico studies using the TAL effector code, predicted many EBEs for the PthA"s" and/or PthC effectors in the promoter regions of genes induced in epicotyls expressing the corresponding TAL effector. Interestingly, we noticed that the EBEs overlap with, or localize close to TATA box elements of the promoters. In addition, despite the different RVD composition between PthA"s" and PthC"s", our results indicate a targeting of functionally-related genes, which further support a model where TAL effectors display the functional convergence by selective evolution as general TATA-binding proteins [24,25]. Finally, we present experimental evidence suggesting that TAL effectors from citrus canker pathogens also function as transcriptional repressors. 


\section{Results}

Transcriptional changes in sweet orange triggered by $X_{c}$ TAL effectors

By extensive gene expression analyses, we had identified numerous genes up-regulated during the canker disease development of sweet orange leaves infiltrated with Xc [26]. To test whether any of those genes are direct targets of TAL effectors, we have undertaken two complementary approaches. First, we performed microarrays assays of orange leaves after bacterial infiltration in the presence or absence of the protein synthesis inhibitor, cycloheximide (Ch), a strategy that has early pinpointed AvrBs3 targets in pepper plants [10,31]. We found that many of the genes induced by Xc at 6 and/or $48 \mathrm{~h}$ after infiltration [26] are also induced by $\mathrm{Xc}$ in the presence of $\mathrm{Ch}$ (Additional file 1), thus indicating that Xc elicit major transcriptional reprograming independent of protein synthesis. Several of these differentially expressed genes are likely involved in terpene and gibberellin synthesis, ethylene production and signaling, cell-wall remodeling, cell division and defense responses (Additional file 1). In particular, we noticed that the ethylene synthesis pathway represented by orthologs of ACC synthase, ACC oxidase and AP2 factor genes, which play roles in cell wall softening [32-34], appears to be a primary mechanism elicited in the host after Xc sensing. On the other hand, defense response genes encoding chitinases, WRKY factors and pathogenesis-related (PR) proteins are also rapidly induced (Additional file 1).

Second, we transiently expressed the Xc TAL effectors PthA2 and PthA4 in sweet orange epicotyls and compared the transcriptional changes relative to epicotyls transformed with GUS as a control (Figure 1A). We selected PthA2 and PthA4 because they form heterodimers and interact with several citrus proteins implicated in transcriptional control [23,35-37]. By inspecting the RVD sequences of PthA2 and PthA4 (Figure 1B), we presumed that they would target common host genes. Consistent with this observation, we found that the transient expression of PthA2 or PthA4 resulted in the up-regulation of a similar group of genes that are functionally related to both defense and disease development (Additional file 2). The genes associated with canker development that were most strongly induced by both PthA2 and PthA4, encode cellwall synthesis and remodeling enzymes, including a glycosyl transferase ortholog of upa15 (CV709535) that is readily up-regulated by AvrBs3 in pepper plants [10]. In addition, the defense response induced genes encode chitinases, PR proteins and an ACC synthase, which are also up-regulated by $\mathrm{Xc}$ in the presence of $\mathrm{Ch}$, thus providing initial evidence that they might be functional targets of PthA2 and PthA4 (Additional files 1 and 2). Notably, numerous genes up-regulated in response to PthA2 or PthA4 are functionally related to auxin and gibberellin synthesis and signaling, cell division and growth, and defense responses (Additional file 2). In particular, we noticed a strong PthA4-dependent induction of genes encoding cell division and expansion proteins including kinesins, tubulins, histones, ribosomal proteins, and orthologs of dem (defective embryo and meristems) and LOB (lateral organ boundary) (Additional file 2). Besides, the transcriptional profile of epicotyls expressing PthA4 is remarkably similar to that of citrus leaves infiltrated with Xc $48 \mathrm{~h}$ postinoculation [26], as shown by the up-regulation of a large number of genes related to auxin synthesis, mobilization, and signaling, including two homologs of the auxin influx carrier protein AUX1 (CV706455, CX053885) [38-40] (see Venn diagram in Additional file 2). In contrast, epicotyls expressing PthA2 showed the up-regulation of many genes implicated in cell-wall remodeling and gibberellin synthesis and signaling, including orthologs of upa6 and upa 7 (alpha-expansins), and upa22 (GA-like protein), respectively, which are putative targets of AvrBs3 in pepper [10,31] (Additional file 2). PthA2 also induced several genes encoding retrotransposons (Additional file 2), which were also reported as off-targets of AvrXa7 in rice [25].

Gene onthology (GO) enrichment analysis showed that while PthA2 modulate several genes categorized in cellwall organization and RNA-dependent DNA replication and integration, PthA4 affected the expression of genes grouped under the microtubule-based movement and cell growth category. In addition, the GO analysis showed that PthA2 and PthA4 commonly regulate a large number of genes involved in carbohydrate (sucrose, glucan and glycoside) metabolism, and cell-wall organization and biogenesis (Figure 2 and Additional file 2). These evidences support the functional convergence between Xc TAL effectors, and is in agreement with recent reports of $X$. oryzae TAL effectors [24,25]. In addition, the common targeting of PthA2 and PthA4 is a strong indicator that they may have additive or even synergistic roles for activation of host genes required for citrus canker susceptibility.

\section{Transcriptional changes in sweet orange triggered by PthC1, a TAL effector of $X$. aurantifolii}

We have shown previously that XaC elicit an HR-type response in sweet orange leaves, which is characterized by the up-regulation of multiple defense-related genes [26]. To examine whether $\mathrm{XaC}$ TAL effectors are involved in the host transcriptional defense response, we cloned two TAL effectors from XaC strain ICMP 8354, designated PthC1 and PthC2. The essential differences between $\mathrm{XaC}$ TAL effectors occur in the number of repeat domains and the nature of the repeat variable diresidues (RVDs), which altogether form the DNA-binding domain of the protein $[12,13]$. PthC1 has 18 RVDs or 17.5 repeat domains, and PthC2 is shorter with only 15 RVDs or 14.5 repeat domains (Figure 1B). Despite the overall structural 


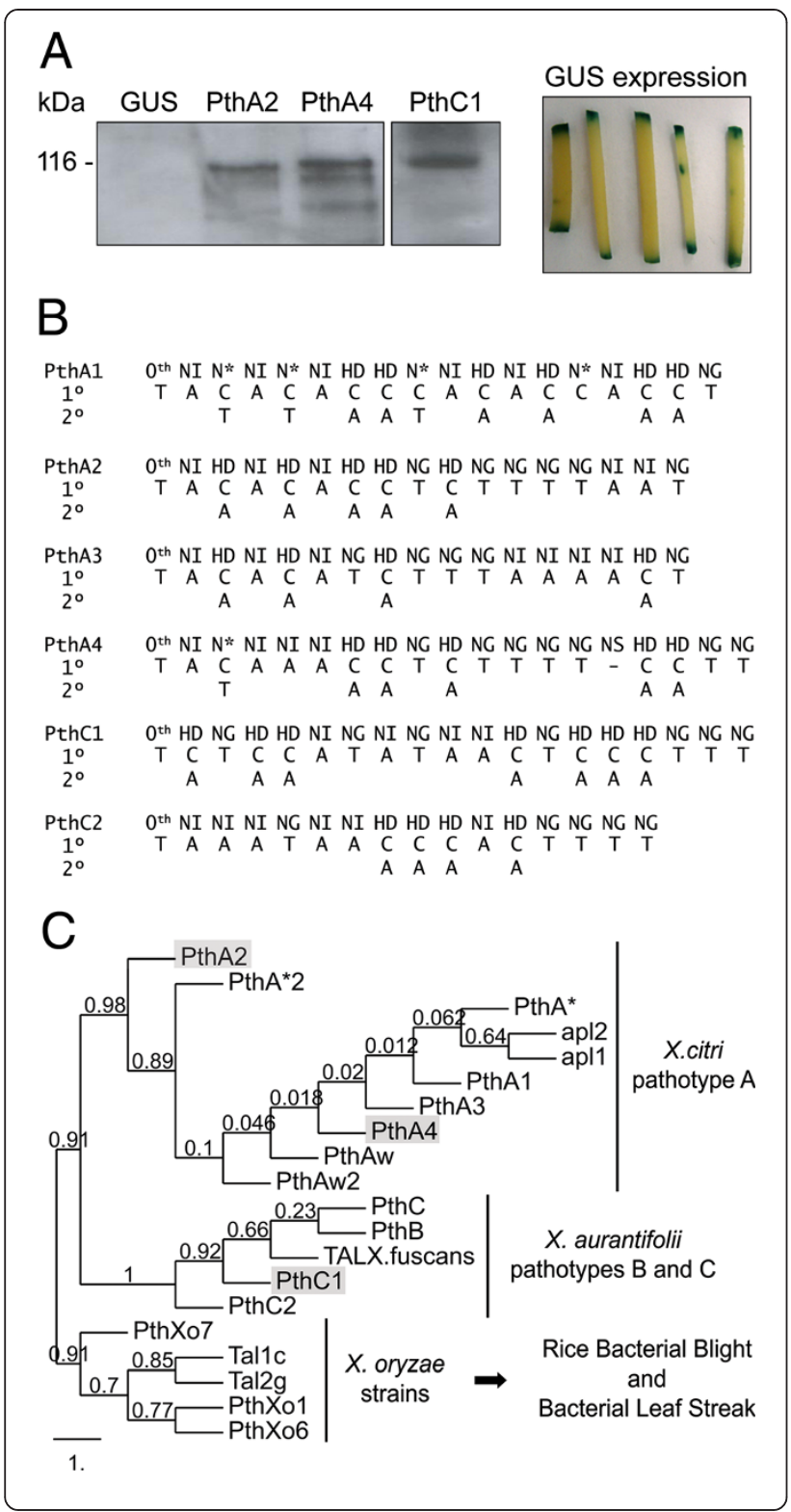

Figure 1 Heterologous expression in citrus epicotyls, RVD sequences and phylogeny of TAL effectors PthA2, PthA4 and PthC1. (A) Western blot of protein extracts from sweet orange epicotyls transfected with A. tumefaciens EHA105 carrying pBl12135S::pthA2 (PthA2), pBI121-35S::pthA4 (PthA4), pBI121-35S::pthC1 (PthC1), or the native plasmid pBI121-35S::uidA (GUS) for control of TAL effectors expression. Total protein from epicotyls expressing PthA2, PthA4 or, PthC1 proteins $(\sim 116 \mathrm{kDa})$ were separated by electrophoresis on 10\% SDS-polyacrylamide gels, transferred to PVDF membranes, and detected with anti-PthA2 serum (left panel). The expression of uidA gene was assayed histochemically for $\beta$ glucuronidase (GUS) activity using 5-bromo-4-chloro-3-indolyl- $\beta$-Dglucuronic acid (X-Gluc) as substrate (right panel). (B) RVD sequence composition of $X$. citri isolate 306 TAL effectors PthA1, PthA2, PthA3 and PthA4, and PthC1 and PthC2 from X. aurantifolii ICMP 8435, aligned with the corresponding predicted DNA targets. According to the TAL effector code, only the first and second bases associated with higher frequency for each RVD are represented. (C) Phylogenetic tree of TAL effectors from different Xanthomonas strains that cause citrus canker disease and blight or leaf streak of rice. The maximum likelihood analysis was built with the PhyML tool using a bootstrapping procedure of 500 repetitions. Only the C-terminal domains ( $\sim 278$ residues) of TAL effectors from Xanthomonas spp. were used for the analysis. The four PthA"s" of Xc strain 306 belong into a group close to other TAL effectors from pathotype A strains; meanwhile, PthCs and PthBs from $X$. aurantifolii integrate a distinct group of pathotypes B and $C$ strains, respectively. The tree is displayed with the TAL effectors from $X$. oryzae strains rooted as outgroup. Amino acid sequences were aligned using MUSCLE and analyzed on phylogenetic pipeline of Phylogeny.fr [41].

similarities with PthA"s" of Xc, PthC1 and PthC2 are phylogenetically more closely related to $\mathrm{PthB}^{\prime \prime} \mathrm{s"}$ and PthC"s" from other pathotype B and C strains, respectively (Figure $1 C$ ), that are distinguished by their limited host range [4,21]. In terms of the RVD composition, PthC1 appears also more similar to PthB and PthC of other citrus canker strains reported to induce weak disease symptoms or hypersensitive response in sweet oranges $[4,21]$. Despite the fact that PthC from a group C strain was not required for the HR elicited on grapefruit [4], we decided to test whether PthC1 induce the expression of defense-related genes in sweet orange, as we observed during $\mathrm{XaC}$ infection [26]. Therefore, we transfected PthC1 in sweet orange epicotyls and compared the transcriptional changes relative to epicotyls expressing PthA2, PthA4, or the GUS gene as reference (Figure 1A). We found that PthC1 elicit not only a different but also an opposite effect of PthA2 and PthA4, because its expression resulted in a general down regulation of genes involved in auxin and gibberellin synthesis and signaling, cell-wall remodeling, cell division, and defense responses (Additional file 3). The fact that auxin and gibberellin promote initial canker pustule formations [27] indicate that PthC1, in contrast to PthA2 and PthA4, do not contribute to canker symptoms in sweet orange. Nevertheless, we found Aux/IAA and bZip orthologous genes repressed by PthC1 (CV713157, CV704184, CK701644, CN182471), which function as 


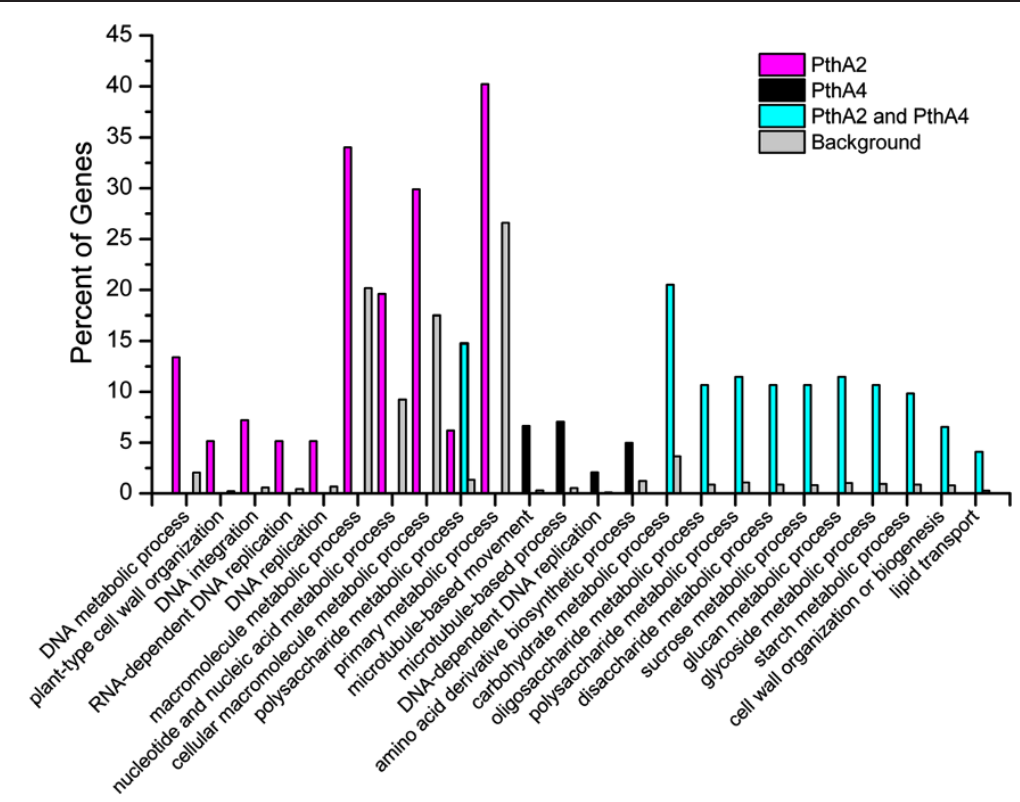

Figure 2 GO enrichment analysis for PthA2 and/or PthA4-regulated genes. GO enrichment analysis performed with agriGO [42], showing that PthA2 and PthA4 modulate several genes in sweet orange associated with canker development. Despite the fact that PthA2 and PthA4 regulate distinct, but related sets of genes implicated in cell-wall remodeling, cell division and growth, they both altered group of genes involved in carbohydrate metabolism and cell-wall organization and biogenesis. The identity of the enriched genes can be found in Additional file 2 .

negative regulators of the auxin and gibberellin signaling pathways affecting plant growth and development [43-45]. In addition, the down-regulation of genes encoding GH3-like enzymes (CF837666, CF837443) [46] and indole-3-acetic acid amido synthase (CV714093) suggest that PthC1 operates to increase the active pools of free auxin. On the other hand, we found no obvious HR-like executor among the genes up-regulated by PthC1 in sweet orange epicotyls (Additional file 3), although an AP2-domain transcription factor orthologous of the tomato Pti4 [47] might be an interesting candidate (Additional file 3).

Together, these data show that PthC1, in contrast to PthA2 and PthA4, regulate a different set of genes in sweet orange. Although these genes may not significantly favor host susceptibility, they do not appear to be elicitors of an HR response either. This idea is consistent with the observation that a knockout mutation of $p t h C$ in a group $C$ strain resulted in loss of pathogenicity on lime, but still triggers the HR response on grapefruit [4].

\section{Computational prediction of EBEs for PthA and PthC in citrus genomes}

The public release of the Citrus sinensis and Citrus clementina genomes together with the TAL effector code of DNA binding $[12,13]$, provides a suitable model to investigate in silico the TAL effector-targeted genes in citrus. Because the computational tools available for TAL effector targets prediction do not yet support analyses of the citrus genomes [24,25,48], we designed a position weight matrix based on TAL effector-DNA association frequencies to predict and score EBEs for Xc and $\mathrm{XaC}$ TAL effectors in citrus gene promoters (Additional file 4). Putative EBEs for the four PthA"s" and the 2 PthC"s" of strains Xc 306 and XaC ICMP 8354, respectively, were identified in nearly one thousand promoters. We then selected the top one hundred best scoring $C$. sinensis promoters ranging from 8.5 to 17.4 for further analysis (Additional file 5). In order to test the performance of our computational matrix analysis, we used the target finder function of the TAL Effector-Nucleotide Targeter 2.0 (TALE-NT) tools [48] to search for PthA "s" and PthC"s" EBEs in the top twenty best scoring promoters. We retrieved virtually the same EBE predictions with equivalent score values [data not shown], indicating a similar achievement between our prediction method and the TALE-NT tools.

Next, we functionally categorized our candidates based on sequence homology to plant, yeast, or animal gene orthologs with known biological function (Additional file 5). In addition to genes implicated in auxin and gibberellin synthesis and signaling, and in cell-wall remodeling, we found a substantial number of genes involved in cell division and morphogenesis, transcription regulation and defense (Additional file 5). Although most of our best scoring promoters do not correspond with the genes identified in our microarray analyses (see below), these data seem to be meaningful because the predicted 
candidates belong to the same functional categories of those up-regulated in citrus epicotyls in response to PthA/PthC expression or in Xc-infiltrated leaves in the presence of Ch (Additional files 1, 2, 3). Remarkably, we predicted two PthC1 targets, orange1.1g035902m.g and orange1.1g035488m.g (Additional file 5), with a strong similarity to the $B s 3$ gene of pepper, which is an HR executor transcriptionally activated by AvrBs3 of $X$. vesicatoria [7]. We also found that several PthA"s" putative targets are involved in abscisic acid (ABA) synthesis, signaling and response, particularly for PthA1 (Additional file 5). Interestingly, some of these genes, including an ABA8-hydroxilase (orange1.1g012199m.g), ABI3 (orange1.1g038867m.g) and ABI3-interacting protein-1 (orange1.1g044737m.g), also participate in the cross-talk between auxin and gibberellin, and in plant growth and development [49-51] (Additional file 5).

\section{Experimental validation of putative gene targets of PthA and PthC effectors}

Although computational identification of TAL effectortargeted genes have been recently conducted for TAL effectors of $X$. oryzae and Xc in their corresponding host genomes, the studies for Xc are largely deficient on experimental validation for novel candidate targets [24,25]. Nevertheless, the combination of in silico predictions with gene expression data, demonstrated to be a suitable strategy to identify new biologically relevant TAL effector targets [52]. Thus, in order to verify our in silico target predictions, we used the whole set of microarray data in our hands to search for experimental evidence of gene regulation of our predicted TAL effector targets. We found that nearly $20 \%$ and $3 \%$ of the computationalpredicted targets were up and down-regulated, respectively, indicating that TAL effectors not only induce but may ultimately repress the expression of host predicted targets (Additional files 1, 2, 3 and 5). Using a cross-check criteria we were able to select targets that 1) are differentially expressed in epicotyls expressing the corresponding TAL effector, 2) are also differentially expressed after infiltration of $\mathrm{Xc}$ in the presence of $\mathrm{Ch}$, and 3) are functionally associated with the mechanisms of canker development or defense response (Table 1).

To verify these data, we first confirmed the TAL effector protein accumulation in epicotyls transiently expressing pthA2, pthA4 or pthC1 (Figure 1A), and subsequently examined the mRNA levels of the predicted targets by quantitative RT-PCR on the transgenic tissues. Totally, sixteen

Table 1 Predicted TAL effector targeted genes in C. sinensis that are transcriptionally regulated by Xc in the presence of $\mathrm{Ch}$ or, by the heterologous expression of the TAL effector

\begin{tabular}{|c|c|c|c|c|}
\hline Microarray data (fold change) & Sweet orange genes with & Homologous gene description & Functional category & References \\
\hline & PthA2 binding sites & & & \\
\hline \multirow[t]{3}{*}{ PthA2 x GUS (4.0) } & orange1.1g032466m.g & Pepper UPA22 (UPA22) & GA response & {$[10,31]$} \\
\hline & orange1.1g031880m.g & Tobacco rac-like GTPase 1 (RAC) & Auxin response & {$[53]$} \\
\hline & orange1.1g001197m.g & Rat transcription activator BRG1 (BRG1) & Cell growth & {$[54]$} \\
\hline \multirow[t]{2}{*}{ PthA2 x GUS $(-3.1)$} & orange1.1g023431m.g & Xyloglucan endotransglucosylase (XET) & Cell growth & {$[55]$} \\
\hline & orange1.1g040761 m.g & Castor bean LOB domain protein (LOB2) & Defense & {$[56]$} \\
\hline \multirow[t]{2}{*}{ PthA2 x GUS $(-3.1)$} & orange1.1g037640m.g & Tobacco UDP-glucosyltransferase (UDPGT) & Defense & {$[57]$} \\
\hline & PthA4 binding sites & & & \\
\hline $\mathrm{Xc}+\mathrm{Ch} \times \mathrm{Ch}(3.8)$ & orange1.1g024897m.g & Tobacco 14-3-3 protein (14-3-3) & Cell growth & {$[58-60]$} \\
\hline PthA4 x GUS (11.4) & orange1.1g017949m.g & Citrus limetta dioxygenase (DIOX) & Cell growth & {$[61,62]$} \\
\hline \multirow[t]{11}{*}{ PthA4 x GUS (5.2) } & orange1.1g018649m.g & Tobacco cysteine proteinase (CP) & Defense & {$[63,64]$} \\
\hline & orange1.1g037138m.g & C. trifoliata NBS-LRR protein (CCNBS1) & Defense & {$[65]$} \\
\hline & PthC1 binding sites & & & \\
\hline & orange1.1g041266m.g & Tomato self pruning-interacting protein 1 (SIP1) & Cell growth & {$[66]$} \\
\hline & orange1.1g010756m.g & Potato $\mathrm{Ca}^{+2}$-dependent protein kinase (CDPK) & Cell growth & {$[67]$} \\
\hline & orange1.1g039072m.g & Potato CC-NBS-LRR protein (CCNBS2) & Defense & {$[68]$} \\
\hline & orange1.1g042296m.g & Sunflower CC-NBS-LRR protein (CCNBS3) & Defense & {$[69]$} \\
\hline & Multiple EBEs & & & \\
\hline & PthA2, PthA4, PthC1 & & & \\
\hline & orange1.1g046669m.g & Tobacco Avr9/Cf9 elicited protein 146 (AE146) & Defense & {$[70]$} \\
\hline & PthA4, PthC1 & & & \\
\hline$X_{C}+C h \times C h(8.8)$ & orange1.1g026556m.g & Aspen LOB domain 1 (LOB1) & Cell growth & {$[71]$} \\
\hline
\end{tabular}


genes implicated in symptom development or defense response, were selected for target validation (Table 1). These candidates were differentially expressed in response to Xc infiltration and also after TAL effector expression in epicotyls, and encoded at least one predicted EBE for the corresponding TAL effector in their promoters. Initially, we tested the expression of four putative PthA2 targets, including an ortholog of the pepper upa22, which encodes a xyloglucan endotransglucosylase (XET), a RACGTPase gene $(R A C)$, and an ortholog of the rat BRG1, implicated in cell wall strengthening, auxin response, and tumor development, respectively (Table 1 ). Consistent with the microarray data (Table 1), the citrus upa22 and the BRG1 genes were slightly but preferentially up-regulated by PthA2 compared to PthA4, PthC1 or GUS in epicotyls; in contrast, $X E T$ was significantly down-regulated in response to PthA2 (Figure $3 \mathrm{~A}$ ). The $R A C$ gene, which was induced in epicotyls expressing PthA2 and PthA4, also appeared down-regulated in tissues expressing PthC1 (Figure 3A). Despite the strong induction of $R A C$ by PthA4 (Figure $3 \mathrm{~A}$ ), we found no good scoring candidate EBEs for PthA4 in the $R A C$ promoter. Presumably, this is part of false negative predictions that account for the current limitations of computational analyses of TAL effector targets [17,52,72,73].

To test the PthA4 candidate targets, we selected 4 genes encoding orthologous of a tobacco 14-3-3 protein, a twodomain dioxygenase (DIOX), a cysteine protease $(\mathrm{CP})$, and a CC-NBS-LRR protein (CCNBS1), which play roles in gibberellin synthesis, cell elongation and defense (Table 1). Consistent with the microarray data (Table 1), we found that the four selected genes were strongly (more than 6 fold-change) up-regulated in epicotyls expressing PthA4, which support the computational prediction of best scoring targets of PthA4 (Figure 3B). Although 14-3-3 and $D I O X$ were induced moderately (between 2 to 3 foldchange) in epicotyls expressing PthC1, no EBEs for PthC1 were identified in these targets.

We also tested the PthC1 predictions using 4 selected candidate genes, including the orthologs of a potato $\mathrm{Ca}^{+2}$ dependent protein kinase (CDPK) and tomato self-pruning interacting protein 1 (SIP1), and two CC-NBS-LRR resistance genes (CCNBS2 and 3) (Table 1). An ortholog of the pepper $B s 3$ gene (orange1.1g035488m.g) was also tested; however, we were not able to detect this gene by qPCR analysis, even using large amounts of cDNA input. We found that SIP1 and CCNBS3 genes were significantly induced in response to $\mathrm{Pth} C 1$ expression relative to GUS, although CCNBS3 was also up-regulated by PthA2 and 4 (Figure $3 C$ ). In addition, SIP 1 and CCNBS2 appeared also induced in response to PthA4 expression. Interestingly, we found an EBE for PthA4 in the SIP1 promoter with a score value of 6.2 that explains the observation. In contrast, $C D P K$ was 3 -fold repressed by PthC1 (Figure 3C).
Altogether, these results partially confirm the TAL effector targets prediction but also suggest that more than one TAL effector might induce the same gene, and that TAL effectors can ultimately cause transcriptional repression of targets, although we have not tested whether this is a direct or indirect (secondary) effect of the protein.

To further investigate these observations, we evaluated the expression of a predicted PthA2 target, a phenylpropanoid:UDP-glucosyltransferase (UDPGT), which was nearly 3-folds down-regulated in PthA2-expressing epicotyls (Table 1). We also tested a predicted target of PthA2, PthA4 and PthC1 encoding an Avr9/Cf9-elicited protein 146 homolog, $A E 146$, as well as two Lateral Organ Boundaries genes, $L O B 1$ and $L O B 2$, indentified as targets of PthA4/PthC1 and PthA2, respectively (Table 1 ). A previous report predicted that the citrus $L O B 1$ was targeted by PthA4 [24]. We found that AE146 is induced in response to PthA2 and PthA4 expression, but in contrast, PthA2, PthA4 and PthC1, down-regulate the expression of UDPGT (Figure 4A). Consistent with our microarray data (Table 1), LOB1 was predominantly induced by PthA4, but repressed by PthC1, while all the three TAL effectors tested induce the expression of LOB2 (Figure 4B).

We also used a pthA4 knockout derivative of Xc, which is not pathogenic in sweet orange neither it induces hyperplasic lesions [23], to analyze the expression levels of candidate PthA4 targets. We found that three of the predicted PthA4 targets, DIOX, CP and 14-3-3, are induced at higher levels in leaves infiltrated with the wild type Xc strain relative to the pthA4-deletion mutant; however, these genes were also up-regulated by the pthA4 mutant relative to water infiltration, which indicates that these genes present a more complex mechanism of induction where PthA4 is not absolutely required (Figure 5A).

We also evaluated the expression of two PthA2 predicted targets $R A C$ and $L O B 2$, and two PthC1 targets LOB1 and SIP1, which were highly up-regulated in epicotyls expressing PthA4 (Figure 3A and C). Although $R A C$ expression was under the level of detection by quantitative PCR (not shown), we found that the transcript accumulation of SIP1 was lower in response to pthA4deletion mutant relative to leaves infiltrated with the wild type Xc (Figure 5A). Similarly, the expression levels of $L O B 1$ and $L O B 2$ were significantly lower in leaves infiltrated with the pthA4-deletion mutant (Figure $5 \mathrm{~B}$ ). Nevertheless, $L O B 1, L O B 2$ and SIP1 were also up-regulated in leaves infiltrated with the pthA4-deletion mutant relative to water-infiltrated leaves, suggesting an alternative mechanism of target induction, potentially by other TAL effectors that our analysis failed to predict.

Taken together these results confirm our previous observations, and point out to $L O B 1, L O B 2, S I P 1, C P$ and $D I O X$ as primary targets of $\mathrm{Xc}$ and $\mathrm{XaC}$ TAL effectors, in particular of PthA4 (Figure 5). 
Figure 3 Gene expression levels of predicted targets of PthA2, PthA4 and PthC1 in epicotyls transfected with the corresponding TAL effector. (A) Quantitative RT-PCR ( $q P C R$ ) of four sweet orange genes with best-scoring effector-binding elements (EBEs) predicted for PthA2 in their promoters. (B) qPCR of four sweet orange genes with best-scoring EBEs predicted for PthA4 in their promoters. Predicted PthA4 target genes are significantly and predominantly up-regulated by PthA4 expression. (C) QPCR of four sweet orange genes with best-scoring EBEs predicted for PthC1 of $\mathrm{XaC}$ in their promoters. The expression levels are the mean of three independent biological replicates. The error bars denote standard deviations whereas asterisks indicate statistically significant

differences $(p<0.05)$ in the mRNA levels in epicotyls expressing the TAL effectors relative to GUS.

\section{PthA and PthC EBEs overlap with or localize close to} TATA box elements in citrus promoters

Including AvrBs3, several TAL effectors bind to EBEs that overlap with TATA-like sequences [6-8,29]. In some cases this causes a downstream shift of the transcriptional start site in the targeted gene, suggesting that TAL effectors might have a similar function of TATA-binding proteins [6-10]. Here, we found that approximately $73 \%$ of the predicted EBEs for PthA"s" and PthC"s" localize between 16 and $300 \mathrm{bp}$ upstream the translation start codon of the genes (Additional file 5). This observation and a recent study in rice suggesting that TAL effectors of $X$. oryzae are predicted to bind within $300 \mathrm{bp}$ upstream the start codon and frequently overlap with TATA-box elements of the promoter [24], prompted us to evaluate whether the overlap or close proximity between TATA boxes and EBE positions, also occurs for TAL effectors of Xc and $\mathrm{XaC}$ in citrus promoters. We found that most of the EBEs predicted for PthA"s" and PthC"s" show a tendency to overlap with, or localize within $30 \mathrm{bp}$ of putativeTATAbox elements (Figure 6 and Additional file 5). For instance, in five of the candidate targets ( $L O B 1, L O B 2, A E 146$, CCNBS1 and CDPK) the EBEs overlapped with a putative TATA box (Additional file 5). Thus, our data suggest that despite the RVD variations among these TAL effectors, they are likely to have an evolutionary selection pressure towards the targeting of TATA-rich regions of host sequences that are critical for the transcriptional regulation.

\section{Discussion}

Despite the fact that many TAL effectors targets and their molecular functions have been coming to light in recent years [3,6-11,74,75], citrus genes directly activated by PthA"s" or PthC"s" effectors, and their role in canker development or host defense against Xanthomonas spp., remain poorly characterized. In this study, we have identified a number of genes putatively targeted by PthA"s" and PthC"s" in sweet orange, and shown that most of them impinge on disease and/or host defense responses. We also observed that PthA2 and PthA4, yet bearing distinct 


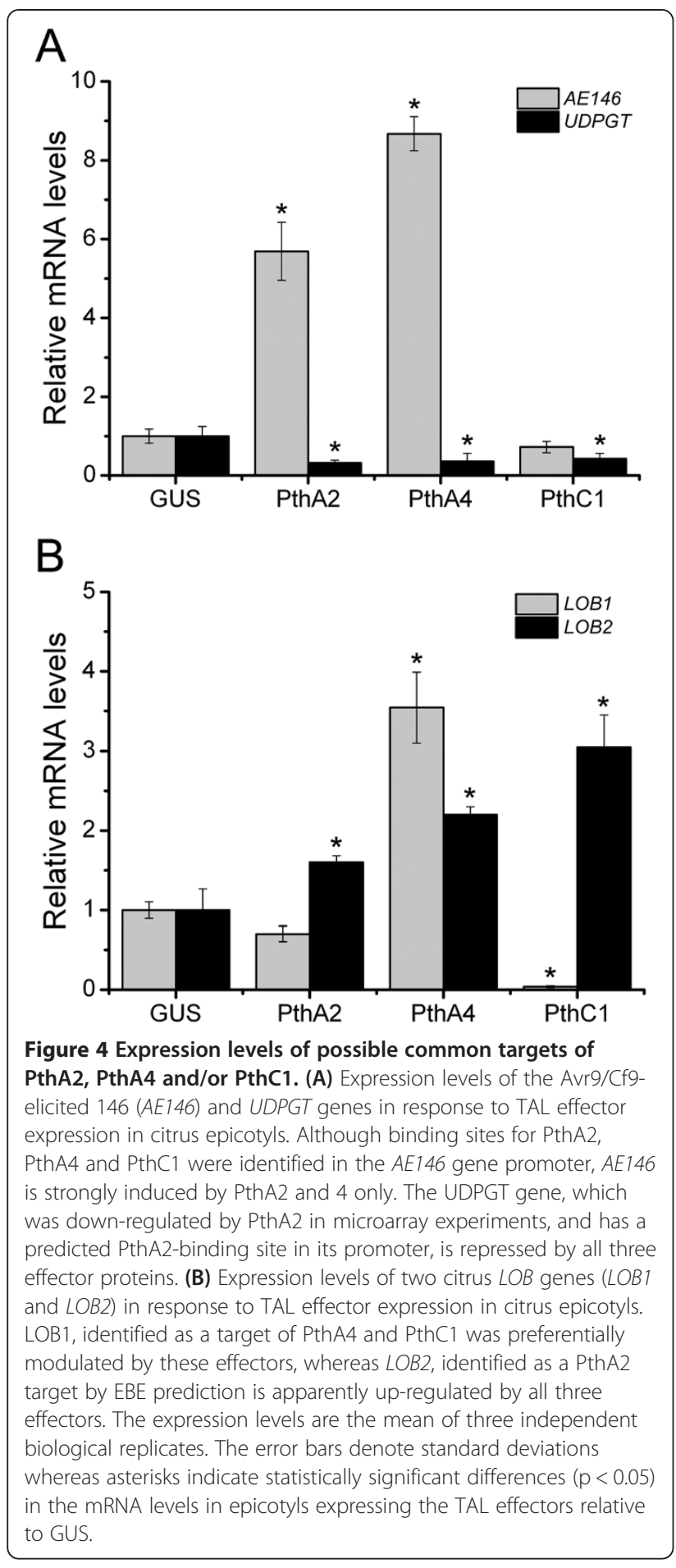

RVDs composition (Figure 1B), exhibit functional convergence, in particular to regulate genes of the auxin and gibberellin synthesis and response pathways, as well as their downstream signaling cascade genes like those for cell wall remodeling, cell division and expansion. In citrus, targeting these hormonal pathways appear to be the headline of canker-causing Xanthomonas spp. since endogenous auxin

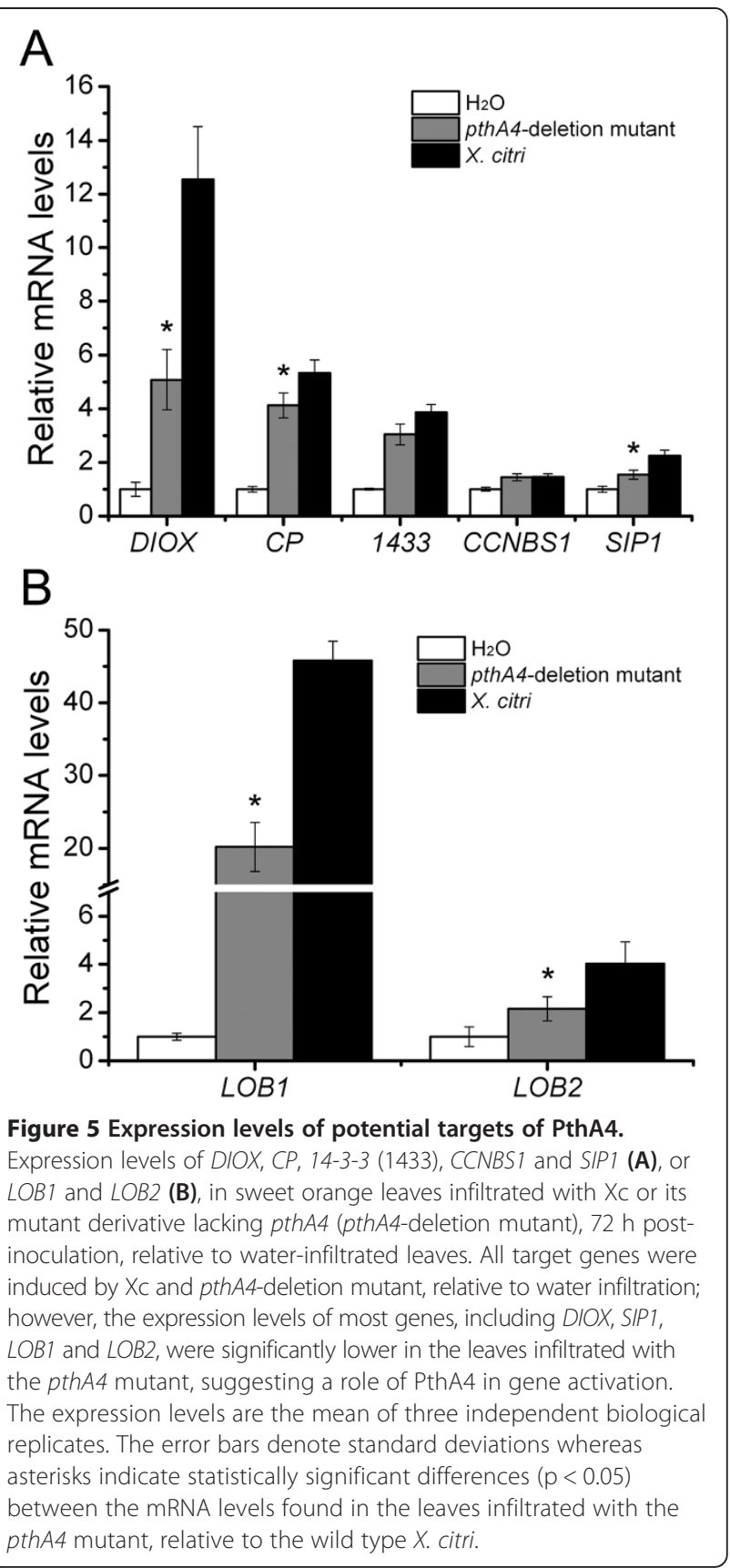

and gibberellin are required for initial canker formation in leaves infiltrated with the pathogen, and the exogenous application of the hormones transcriptionally regulate specific genes also induced by Xc during the onset of infection $[26,27]$. How these hormones contribute to the canker disease needs further exploration, but it is clear their relationship with the canker symptoms, hypertrophy and hyperplasia of mesophyll cells [2], which generate enough internal pressure to prompt the epidermal rupture and facilitate pathogen release to the leaf surface for disease propagation [21,27]. Besides, auxin also increase the 


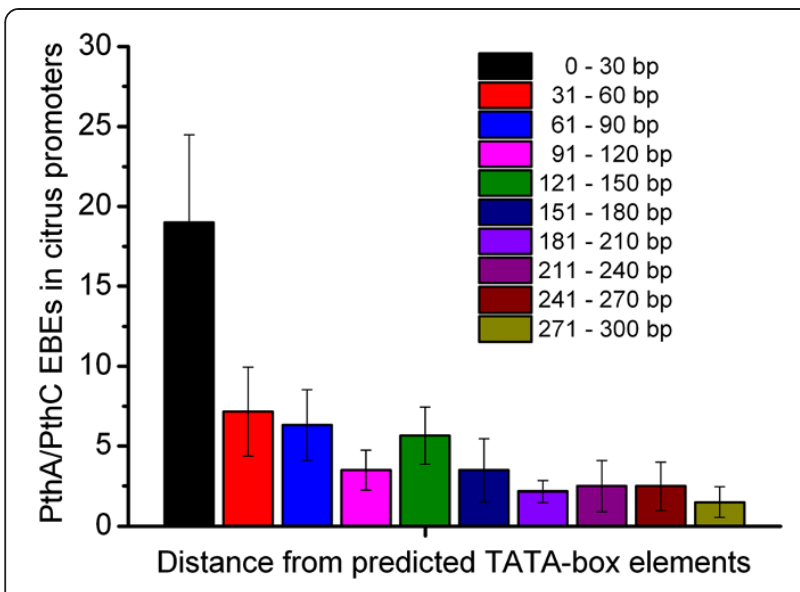

Figure 6 Distribution of average distance of predicted EBEs relative to TATA-like elements in citrus promoters. Possible overlap between TATA box and PthA/PthC-binding site positions in the citrus promoters predicted as targets of PthA/PthC proteins. The great majority of PthA and PthC-binding sites overlap with, or are located within $30 \mathrm{bp}$ of the predicted TATA-box elements in the corresponding citrus promoters.

host susceptibility on other plant-pathogen interactions [76-79], pointing it out as a conserved mechanism of biotrophic microbes to elicit cell wall softening to e.g., leak nutrients from the host cell, and/or to improve effectors translocation that promote host susceptibility and bacterial fitness. Overall, it is tempting to speculate that, in the case of the citrus canker pathogens, manipulating the auxin signaling pathway via TAL effector-targeting would be an effective way to disarm host defense responses for bacterial survival and pathogenicity. Notably, many of the AvrBs3 up-regulated (UPA) genes are also auxinresponsive and some of them including upa7, upa15, upa17 and upa20, are known to enhance cell hypertrophy and the synthesis of cell-wall polymers [8,10,31].

These data reflect on recent studies suggesting that the redundancy and convergence in TAL effector repertories occurring within and across $X$. oryzae strains, respectively, may be a conserved feature of TAL effector evolution as a consequence of an arms race of the host-bacteria interaction $[24,25]$. The biological meaning of such functional redundancy of TAL effectors in strain 306, particularly between PthA2 and PthA4, denote a cooperative, or eventually a synergistic role of these effectors as transcriptional activators (Figures 3, 4, 5, Additional files 2 and 5). In addition, it is interesting to note that PthA2 physically interacts with PthA4, and that both proteins bind independently to the C-terminal domain of RNA Pol II [37]. Hence, TAL effector-mediated transcriptional regulation in citrus appears to be further influenced by the multiple protein-protein interactions occurring at the assembly locus of RNA Pol II. According with this assumption, the up-regulation of $L O B 1$ and $L O B 2$ in epicotyls expressing PthA2 or PthA4 (Figure 4B), and in sweet orange leaves infiltrated with $\mathrm{Xc}$ or its pthA4 mutant derivative (Figure 5B), emerges as an evident example of a redundant targeting of a presumably major gene for canker susceptibility. We also predicted another gene encoding a LOB-domain protein targeted by PthA3, orange1.1g048558m.g (Additional file 5). Interestingly, $L O B$ genes have been associated to auxin signaling pathways, including cell growth control and organ development $[56,71,80]$. From an evolutionary point of view, it seems advantageous for a single Xc strain to target a family of potential susceptibility genes, i.e. $L O B$ genes with different TAL effectors, which function cooperatively or synergistically, because it will assure the induction of the critical set of genes involved in disease symptoms development. The observation is convincing since it implies a mechanism that the pathogen uses to overcome potential natural polymorphisms in TAL effector targeted promoters, in particular those occurring in susceptibility genes among different host varieties [6].

Beyond the functional redundancy of Xc TAL effectors, we found that PthA4 predominantly induce genes encoding ribosomal proteins and proteins of cell division and growth, like kinesins, tubulins and histones (Additional file 2). This is noteworthy because PthA4 also physically interacts with the citrus MAF1 protein (CsMAF1), which is a negative regulator of RNA Pol III that controls ribosome biogenesis and suppresses canker symptoms $[23,36]$. Thus, the specific PthA4-induction of ribosomal protein genes appears to be a causal feedback mechanism of ribosome biogenesis that is required for cell division and growth. On the other hand, although PthA2 does not interact with CsMAF1, it binds to and inhibits the prolylisomerase activity of the citrus cyclophilin CsCYP, a putative negative regulator of the RNA Pol II complex $[23,35,37,81]$. Therefore, it remains to be determined how these protein specific interactions between TAL effectors and components of RNA Pol II and III complexes affect the outcome of the host expression profiles in response to bacterial infection.

In contrast to PthA"s"-induced genes, epicotyls expressing PthC1 showed a general down-regulation of auxin and gibberellin response genes suggesting that this TAL effector is not an elicitor of susceptibility. For instance, $L O B 1$ that is induced by PthA4, appears significantly down-regulated by PthC1 (Figure 4B), which is consistent with the PthC1-mediated repression of auxin response genes, since LOB proteins have also been implicated in auxin signaling $[80,82]$. However, it remains to be determined whether the general down-regulation of the auxin responsive genes by $\mathrm{PthC} 1$ in sweet orange is the major cause for the lack of host susceptibility (i.e. no hyperplasic lesions) after infiltration of sweet orange with $\mathrm{XaC}[26]$. 
In pepper plants ecotype ECW-30, the Bs3 resistance gene induced by the $X$. vesicatoria TAL effector AvrBs3, executes an HR response after bacterial infiltration [7]. Our computational analyses have predicted EBEs of PthC1 in the promoters of two sweet orange genes orthologous to Bs3, orange1.1g035488m.g and orange1.1g035902m.g (Additional file 5); however, we were not able to detect their expression in response to $\mathrm{PthC} 1$ or after $\mathrm{XaC}$ infiltration (Additional file 3), and neither were them detected by any other gene expression analyses we conducted before i.e., differential display PCR and suppression subtractive hybridization [26]. Besides, though the results discussed above indicate that $\mathrm{XaC}$ cannot induce host susceptibility, we do not yet discard the possibility that an HR-like elicitor is mediating the sweet orange defense against $\mathrm{XaC}$.

It has been verified and predicted that nodulin and flavone-3-hydroxylase (F3H) genes, respectively, represent common targets of Xanthomonas ssp. TAL effectors $[11,24,25]$. Here, we found four nodulin-related genes, which are significantly up-regulated in sweet orange leaves infiltrated with Xc in the presence of Ch, DN620509, or in epicotyls expressing PthA2, CX675781, and PthA4, DN958192 and CV710110. However, we were not able to predict EBEs for PthA"s" in their promoters suggesting a potential gap for false negative predictions of computational analyses, or eventually indicating that their induction is consequential of other primary targets of the TAL effectors. On the other hand, we predicted EBEs of PthA and/or PthC in the promoters of the nodulin-related genes orange1.1g007766m.g and orange1.1g042021m.g, but none of these genes were up-regulated in our microarray dataset (Additional files 1,2 and 5).

One of the predicted targets of PthA4 is the citrus dioxygenase gene $D I O X$ (Table 1, Figures $3 \mathrm{~B}$ and $5 \mathrm{~A}$, Additional file 5) that is similar to the rice gene $F 3 H$, also a predicted target of TAL effectors from $X$. oryzae strains [25]. Although the $\mathrm{F} 3 \mathrm{H}$ was linked to flavonoid biosynthesis [25], both $F 3 H$ and DIOX are similar to Gibberellin-20-Oxidases (GA20ox), a group of enzymes that catalyze gibberellin biosynthesis [83]. Interestingly, as observed for the $L O B$ genes, a citrus gene encoding a putative GA20 oxidase (orange1.1g019643m.g) was identified as a target of PthA1, PthA2 and PthA3 (Additional file 5). This protein has the same domain architecture found in DIOX, which suggests they are functional orthologs. In addition, both PthA4 and PthC1 transactivate a regulator of gibberellin synthesis namely 14-3-3, and a SIP1 gene in epicotyls (Figure 3) whose protein products interact with a SELF-PRUNING factor involved in the control plant architecture and flowering of tomato [58,66,84]. These evidences together support the susceptibility effect of inducing gibberellin genes during the process of infection.

Another outcome of our study is the proximity of the predicted EBEs relative to putative TATA boxes of promoter regions (Figure 6). This is in line with the fact that EBEs for $X$. oryzae TAL effectors have been also identified close to TATA elements in rice promoters [6]. Similarly, AvrBs3 binding sites are found within $100 \mathrm{bp}$ upstream of the transcription start site [10], raising the idea that TAL effectors might functionally replace general TATA-binding factors, as recently proposed [24]. In addition, our data indicates that TAL effectors can function as transcriptional repressors, in particular PthC1, as discussed above (Additional files 2 and 3; Figures 3 and 4).

\section{Conclusion}

In conclusion, we have identified candidate targets of PthA "s" and PthC"s" in citrus that will not only strengthen our understanding on canker symptoms formation, but also provide novel information about host susceptibility or defenses against Xanthomonas pathogens, which will assist in the selection and generation of canker resistant plants.

\section{Methods}

\section{Bacterial strains, plasmids and growth conditions}

PthA2 and PthA4 were amplified from the Xc strain 306 [85] and cloned into pET28a and pBI121 for bacteria and plant expression, as previously described [35]. Plasmids were introduced into E. coli strain DH5alpha and/or Agrobacterium tumefaciens strain EHA105 by electroporation. E. coli cells were incubated at $37^{\circ} \mathrm{C}$ in Luria-Bertani (LB) medium, whereas $\mathrm{Xc}$ and $A$. tumefaciens were grown in LB without $\mathrm{NaCl}$ at $28^{\circ} \mathrm{C}$ and in YEP (Bacto peptone $10 \mathrm{~g} / \mathrm{l}$, $\mathrm{NaCl} 5 \mathrm{~g} / \mathrm{l}$, Yeast extract $10 \mathrm{~g} / \mathrm{l}$, and Agar $15 \mathrm{~g} / \mathrm{l}$ ) at $30^{\circ} \mathrm{C}$, respectively [86]. Bacterial cultures were grown at different time periods until they reached the desired optical densities. Antibiotics were added to the media in the following final concentrations: ampicillin, $100 \mu \mathrm{g} / \mathrm{ml}$; kanamycin, $50 \mu \mathrm{g} / \mathrm{ml}$; rifampicin, $50 \mu \mathrm{g} / \mathrm{ml}$; streptomycin, $25 \mu \mathrm{g} / \mathrm{ml}$.

\section{Plant material, bacterial infiltration}

Six-month-old plants of sweet orange "Pera" were obtained from certified nurseries and kept in a growth room at $25-28^{\circ} \mathrm{C}$ with a $14 \mathrm{~h}$ light photoperiod. For plant infiltration, Xc strains were inoculated from single colony plates and grown over night at $28^{\circ} \mathrm{C}$ in liquid LB without $\mathrm{NaCl}$. Cells colonies were suspended in sterile water to an optical density at $600 \mathrm{~nm}\left(\mathrm{OD}_{600}\right)$ of 0.1 (nearly $10^{6} \mathrm{CFU} / \mathrm{ml}$ ). Leaves were infiltrated with bacterial suspensions in water or, in $50 \mu \mathrm{M}$ cycloheximide (Ch) (Sigma-Aldrich, USA). Water and Ch only were independently infiltrated as mock controls. For quantitative PCR (qPCR) assays, fully expanded "Pera" leaves were infiltrated with a water suspension $\left(\mathrm{OD}_{600}=0.1\right)$ of wild type Xc strain 306, or its pthA4-deletion mutant derivative [23]. 


\section{Cloning TAL effectors from $X$. aurantifolii}

PthC genes were PCR amplified using total DNA extracted from the $\mathrm{XaC}$ strain ICMP 8435 [26] as template. Primers targeting conserved 5' and 3' regions were designed based on the four available Xc pthA genes (5'-CATATGGATCC CATTCGTTCG-3' and 5'-GAATTCTCACTGAGGCAA TAGCTC-3'). PCR products were amplified using the Pfu turbo DNA polymerase in a $50 \mu \mathrm{L}$ reaction, following the supplier's instructions (Stratagene, USA), with an annealing temperature of $52^{\circ} \mathrm{C}$ and extension time of $4 \mathrm{~min}$. PCR products were gel-purified and cloned into of pET28a vector using the restriction sites $N d e \mathrm{I} / E c o R I$. At least twenty independent clones were analyzed by restriction mapping with SspI enzyme, or by DNA sequencing and only two different variants designated PthC1 and PthC2 were identified. None of the PthA effectors of Xc isolate 306 were found in our screening of XaC TAL effectors sequences.

\section{Expression of Xanthomonas TAL effectors in citrus epicotyls}

Agrobacterium strains transformed with pBI121 vector (bearing the uidA gene under the control of the CaMV $35 \mathrm{~S}$ promoter) or its derivative carrying the TAL effectors pthA2, pthA4 or $p t h C 1$ in place of the uidA gene, were used to transform sweet orange. Epicotyls from young plantlets of Citrus sinensis 'Hamlin' were wounded, transversely sectioned and incubated at room temperature $\left(21^{\circ} \mathrm{C}\right)$ for $15 \mathrm{mi}-$ nutes in a fresh suspension of $A$. tumefaciens $\left(\mathrm{OD}_{600}=0.6\right)$ containing $100 \mu \mathrm{M}$ acetosyringone. Co-cultivation assays were conducted on semi-solid 1x Murashige and Skoog medium supplemented with $25 \mathrm{~g} / \mathrm{l}$ sucrose, vitamin cocktail $(10 \mathrm{mg} / \mathrm{l}$ thiamine- $\mathrm{HCl}, 10 \mathrm{mg} / \mathrm{l}$ pyridoxine, $1 \mathrm{mg} / \mathrm{l} \mathrm{nico-}$ tinic acid, $0.4 \mathrm{mg} / \mathrm{l}$ glycine), $100 \mathrm{mg} / \mathrm{l}$ of $m y o$-inositol and $0.2 \mathrm{mg} / \mathrm{l}$ of 2,4-dichlorophenoxyacetic acid ( $\mathrm{pH} 5.8$ ) during $72 \mathrm{~h}$ in dark [87]. Transformation efficiency was confirmed by western blot analyses and histochemical GUS assay prior to RNA isolation for microarray and qPCR analysis.

\section{Western blot detection of PthA/PthC expression}

Citrus epicotyls transfected with the native pBI121 vector or, its derivatives carrying the effector genes $p t h A 2$, pthA4 or $p t h C 1$, were grinded to homogeneity in SDS-PAGE sample buffer and resolved on a $10 \%$ SDS-polyacrylamide gel. The proteins were transferred onto PVDF membranes and probed with anti-PthA2 serum as previously described [35].

\section{GUS assay}

The A. tumefaciens strain EHA105 transformed with the pBI121 vector carrying the reporter gene uidA, which encodes beta-D-glucuronidase (GUS), was transfected in citrus epicotyls as described previously and the transient expression of GUS was tested using colorimetric assay $72 \mathrm{~h}$ after bacteria-tissue co-cultivation [88].

\section{RNA isolation and microarray and RT-qPCR analysis}

Messenger RNA (mRNA) was extracted from infiltrated leaves or from transformed epicotyls as described previously [26]. For microarray hybridization, approximately $0.6 \mu \mathrm{g}$ of mRNA was used to synthesize cDNAs, which were subsequently used as template to generate the biotin-labeled complementary RNAs (cRNAs) using the One-Cycle target labeling assay (Affymetrix). GeneChips of citrus genome arrays (Affymetrix) were hybridized with cRNAs following standard instructions of Affymetrix kits. The hybridized arrays were rinsed, stained and scanned with an Affymetrix Genechip Scanner 3000-7G. Two CEL files per treatment, corresponding to biological replicates, were analyzed with the ArrayAssit software package (ArrayAssit x.5, Stratagene, USA) using the MAS5 algorithm.

Total RNA samples were prepared from sweet orange leaves infiltrated with Xc, its pthA4-deletion mutant, or water as control, $72 \mathrm{~h}$ after bacterial inoculation, using the Trizol method (Invitrogen, Carlsbad, CA) and subsequently treated with DNase I (Promega, Madison, WI). Nearly $10 \mu \mathrm{g}$ of total RNA was reverse-transcribed using the Maxima First Strand cDNA Synthesis Kit (Fermentas) according to the supplier's instructions, and used as template in real-time qPCR reactions conducted in 96-well plates. Primer sequences (Additional file 6) corresponding to the Citrus sinensis genes listed in Table 1 were designed using the Primer Express 2.0 software (ABI, Foster City, CA). Each $25-\mu \mathrm{L}$ qPCR reaction was composed by $12.5 \mu \mathrm{L}$ of SYBR green $2 \times$ master mix (ABI, Foster City, CA), $1 \mu \mathrm{L}$ of forward and reverse primer mix $(7.5 \mu \mathrm{M}), 1 \mu \mathrm{L}$ of cDNA and $10.5 \mu \mathrm{L}$ of diethyl pyrocarbonate-treated water. qPCR amplifications were carried out using the 7500 system "Universal" cycle condition in an ABI Prism 7300 instrument (Applied Biosystems, Foster City, CA). The Citrus sinensis gene encoding a malate translocator was selected as internal control for normalization [86]. Total RNA from three different leaves were used in qPCR reactions as independent biological replicates, and three technical replicates for each biological sample were considered for statistical T-tests to determine the significant changes of gene expression across the treatments.

\section{In silico prediction of TAL effector binding sites}

A position-specific weight matrix was designed based on the TAL code of associations frequencies between DNA bases and RVDs, and used to score putative effector binding elements (EBEs) of PthA1, PthA2, PthA3 and PthA4 of Xc strain 306, and PthC1 and PthC2 of XaC strain ICMP 8435 , considering a thymidine $(\mathrm{T})$ at position -1 of the EBE as preferential base $[12,13]$. The algorithm was used to perform systematic similarity searches within $1500 \mathrm{bp}$ of promoter regions relative to the translation start site of genes annotated in the 
genomes of C. clementina (http://www.citrusgenomedb. org/species/clementina/genome1.0) and C. sinensis (http:// www.citrusgenomedb.org/species/sinensis/genome1.0). Identification of orthologous relationships between these two species was based on nucleotide sequence similarities (BLASTn) and best bidirectional hit (BBH) method $[89,90]$. Reciprocal sequence similarity searches between C. clementina and $C$. sinensis genes were performed using the BLASTn algorithm [91], with an E-value cutoff of $1 \mathrm{xE}^{-20}$, and a homemade Perl script to parse both BLASTn outputs to identify the BBH BLAST relationships (Additional file 4). The search was performed using the MOODS algorithm [92], which provided a list of possible EBEs for the PthA/PthC TAL effectors with a corresponding score for each sequence. The p-value cutoff was set to 0.001 in order to reduce false positives prediction alignments.

The final set of $C$. sinensis promoters having one or more putative PthA/PthC binding sites (top 100 hits) was derived from a conserved region analysis between the $C$. clementina and $C$. sinensis orthologous promoters, an approach that is widely used to identify new regulatory motifs in many organisms [93-95]. Thus, only the citrus genes with PthA/PthC binding sites in both $C$. sinensis and C. clementina promoters were selected.

\section{In silico TATA-box prediction}

The DNA sequences corresponding to the promoters of C. sinensis genes having potential EBEs (top hits) were submitted to the Plant TATA-box prediction server using the TSSP program [96] at the http://linux1.softberry.com/ berry.phtml site.

\section{Availability of supporting data}

The sequences of PthC1 and PthC2 were deposited in the GeneBank as ADI48327 and ADI48328 accessions, respectively. The microarray data files (Affymetrix CEL files) for all the experiments described here have been deposited to GEO under the superseries GSE51379.

\section{Additional files}

Additional file 1: Microarray analyses of sweet orange leaves infiltrated with Xc in the presence or absence of cycloheximide (Ch), $8 \mathrm{~h}$ after bacterial inoculation.

Additional file 2: Microarray analyses of sweet orange epicotyls expressing PthA2 or PthA4.

Additional file 3: Microarray analyses of sweet orange epicotyls expressing PthC1.

Additional file 4: Perl script developed to parse both BLASTn outputs to identify the best bidirectional hit (BBH) BLAST relationships.

Additional file 5: Top one hundred best scoring C. sinensis promoters with predicted EBEs for PthA and PthC proteins. Additional file 6: List of primers used in the qPCR experiments.
Competing interests

The authors declare that they have no competing financial interest.

\section{Authors' contribution}

Conceived and designed the experiments: ALAP, MFC, RAC and CEB, Performed the experiments: ALAP, MFC, VYA, MLPO, MND, JCS and CEB, Analyzed the data: ALAP, MFC, VYA, MND, RAC and CEB, Wrote the paper: RAC and CEB. All authors read and approved the final manuscript.

\section{Acknowledgements}

This work was supported by São Paulo Research Foundation (FAPESP grants 2010/00634-1 and 2011/20468-1) and Conselho Nacional de

Desenvolvimento Científico e Tecnológico (CNPq).

\section{Author details}

${ }^{1}$ Laboratório Nacional de Biociências, Centro Nacional de Pesquisa em Energia e Materiais, R. Giuseppe Máximo Scolfaro 10000, Campinas, SP 13083-970, Brazil. ²Departamento de Genética, Evolução e Bioagentes, Instituto de Biologia, Universidade Estadual de Campinas, Campinas, SP 13083-970, Brazil. ${ }^{3}$ Present address: U.S. Department of Agriculture, U.S. Horticultural Research Laboratory, 2001 South Rock Road, Fort Pierce, FL 34945, USA. ${ }^{4}$ Present address: Department of Plant Pathology and Plant-Microbe Biology, Cornell University, Ithaca, NY 14853, USA.

Received: 21 October 2013 Accepted: 18 February 2014

Published: 25 February 2014

\section{References}

1. Bonas U, Stall RE, Staskawicz B: Genetic and structural characterization of the avirulence gene avrBs3 from Xanthomonas campestris pv. vesicatoria. Mol Gen Genet 1989, 218:127-136.

2. Duan Y, Castañeda A, Zhao G, Erdos G, Gabriel D: Expression of a single, host-specific, bacterial pathogenicity gene in plant cells elicits division, enlargement, and cell death. Mol Plant Microbe Interact 1999, 12:556-560.

3. Yang B, Sugio A, White FF: Os8N3 is a host disease-susceptibility gene for bacterial blight of rice. Proc Natl Acad Sci U S A 2006, 103:10503-10508.

4. Al-Saadi A, Reddy J, Duan Y, Brunings A, Yuan Q, Gabriel D: All five hostrange variants of Xanthomonas citri carry one pthA homolog with 17.5 repeats that determines pathogenicity on citrus, but none determine host-range variation. Mol Plant Microbe Interact 2007, 20:934-943.

5. Shiotani H, Fujikawa T, Ishihara H, Tsuyumu S, Ozaki K: A pthA homolog from Xanthomonas axonopodis pv. citri responsible for host-specific suppression of virulence. J Bacterio/ 2007, 189:3271-3279.

6. Antony G, Zhou J, Huang S, Li T, Liu B, White F, Yang B: Rice xa13 recessive resistance to bacterial blight is defeated by induction of the disease susceptibility gene Os-11 N3. Plant Cell 2010, 22:3864-3876.

7. Römer $P$, Hahn S, Jordan T, Strauss T, Bonas U, Lahaye T: Plant pathogen recognition mediated by promoter activation of the pepper $B s 3$ resistance gene. Science 2007, 318:645-648.

8. Kay S, Hahn S, Marois E, Hause G, Bonas U: A bacterial effector acts as a plant transcription factor and induces a cell size regulator. Science 2007, 318:648-651.

9. Römer P, Strauss T, Hahn S, Scholze H, Morbitzer R, Grau J, Bonas U, Lahaye $\mathrm{T}$ : Recognition of AvrBs3-like proteins is mediated by specific binding to promoters of matching pepper Bs3 alleles. Plant Physiol 2009, 150:1697-1712.

10. Kay S, Hahn S, Marois E, Wieduwild R, Bonas U: Detailed analysis of the DNA recognition motifs of the Xanthomonas type III effectors AvrBs3 and AvrBs3Deltarep16. Plant J 2009, 59:859-871.

11. Yu Y, Streubel J, Balzergue S, Champion A, Boch J, Koebnik R, Feng J, Verdier V, Szurek B: Colonization of rice leaf blades by an African strain of Xanthomonas oryzae pv. oryzae depends on a new TAL effector that induces the rice nodulin-3 Os11N3 gene. Mol Plant Microbe Interact 2011, 24:1102-1113.

12. Boch J, Scholze H, Schornack S, Landgraf A, Hahn S, Kay S, Lahaye T, Nickstadt A, Bonas U: Breaking the code of DNA binding specificity of TAL-type III effectors. Science 2009, 326:1509-1512.

13. Moscou M, Bogdanove A: A simple cipher governs DNA recognition by TAL effectors. Science 2009, 326:1501.

14. Murakami MT, Sforça ML, Neves JL, Paiva JH, Domingues MN, Pereira AL, Zeri AC, Benedetti CE: The repeat domain of the type III effector protein 
PthA shows a TPR-like structure and undergoes conformational changes upon DNA interaction. Proteins 2010, 78:3386-3395.

15. Deng D, Yan C, Pan X, Mahfouz M, Wang J, Zhu JK, Shi Y, Yan N: Structural basis for sequence-specific recognition of DNA by TAL effectors. Science 2012, 335:720-723.

16. Mak AN, Bradley P, Cernadas RA, Bogdanove AJ, Stoddard BL: The crystal structure of TAL effector PthXo1 bound to its DNA target. Science 2012, 335:716-719.

17. Stella S, Molina R, Yefimenko I, Prieto J, Silva G, Bertonati C, Juillerat A, Duchateau P, Montoya G: Structure of the AvrBs3-DNA complex provides new insights into the initial thymine-recognition mechanism. Acta Crystallogr D Biol Crystallogr 2013, 69:1707-1716.

18. Li T, Huang S, Jiang WZ, Wright D, Spalding MH, Weeks DP, Yang B: TAL nucleases (TALNs): hybrid proteins composed of TAL effectors and Fokl DNA-cleavage domain. Nucleic Acids Res 2011, 39:359-372.

19. Miller JC, Tan S, Qiao G, Barlow KA, Wang J, Xia DF, Meng X, Paschon DE, Leung E, Hinkley SJ, Dulay GP, Hua KL, Ankoudinova I, Cost GJ, Urnov FD, Zhang HS, Holmes MC, Zhang L, Gregory PD, Rebar EJ: A TALE nuclease architecture for efficient genome editing. Nat Biotechnol 2011, 29:143-148.

20. Zhang F, Cong L, Lodato S, Kosuri S, Church GM, Arlotta P: Efficient construction of sequence-specific TAL effectors for modulating mammalian transcription. Nat Biotechnol 2011, 29:149-153.

21. Brunings AM, Gabriel DW: Xanthomonas citri: breaking the surface. Mol Plant Pathol 2003, 4:141-157.

22. Yan Q, Wang N: High-throughput screening and analysis of genes of Xanthomonas citri subsp. citri involved in citrus canker symptom development. Mol Plant Microbe Interact 2012, 25:69-84.

23. Soprano AS, Abe VY, Smetana JH, Benedetti CE: Citrus MAF1, a repressor of RNA Pol III, binds the Xanthomonas citri canker elicitor PthA4 and suppresses citrus canker development. Plant Physiol 2013, 163:232-242.

24. Grau J, Wolf A, Reschke M, Bonas U, Posch S, Boch J: Computational predictions provide insights into the biology of TAL effector target sites. PLoS Comput Biol 2013, 9:e1002962.

25. Pérez-Quintero AL, Rodriguez-R LM, Dereeper A, López C, Koebnik R, Szurek B, Cunnac S: An improved method for TAL effectors DNA-binding sites prediction reveals functional convergence in TAL repertoires of Xanthomonas oryzae strains. PLOS One 2013, 8:e68464.

26. Cernadas RA, Camillo LR, Benedetti CE: Transcriptional analysis of the sweet orange interaction with the citrus canker pathogens Xanthomonas axonopodis pv. citri and Xanthomonas axonopodis pv. aurantifolii. Mol Plant Pathol 2008, 9:609-631.

27. Cernadas RA, Benedetti CE: Role of auxin and gibberellin in citrus canker development and in the transcriptional control of cell-wall remodeling genes modulated by Xanthomonas axonopodis pv. citri. Plant Sci 2009, 177:190-195.

28. Depuydt S, Hardtke CS: Hormone signalling crosstalk in plant growth regulation. Curr Biol 2011, 21:R365-R373.

29. Gu K, Yang B, Tian D, Wu L, Wang D, Sreekala C, Yang F, Chu Z, Wang GL, White FF, Yin Z: R gene expression induced by a type-III effector triggers disease resistance in rice. Nature 2005, 435:1122-1125.

30. White FF, Yang B: Host and pathogen factors controlling the riceXanthomonas oryzae interaction. Plant Physiol 2009, 150:1677-1686.

31. Marois E, van den Ackerveken G, Bonas U: The Xanthomonas type III effector protein AvrBs3 modulates plant gene expression and induces cell hypertrophy in the susceptible host. Mol Plant Microbe Interact 2002, 15:637-646

32. Tatsuki M, Haji T, Yamaguchi M: The involvement of 1aminocyclopropane-1-carboxylic acid synthase isogene, Pp-ACS1, in peach fruit softening. J Exp Bot 2006, 57:1281-1289.

33. Tacken E, Ireland H, Gunaseelan K, Karunairetnam S, Wang D, Schultz K, Bowen J, Atkinson RG, Johnston JW, Putterill J, Hellens RP, Schaffer RJ: The role of ethylene and cold temperature in the regulation of the apple POLYGALACTURONASE1 gene and fruit softening. Plant Physiol 2010, 153:294-305.

34. Yin XR, Allan AC, Chen KS, Ferguson IB: Kiwifruit EIL and ERF genes involved in regulating fruit ripening. Plant Physiol 2010, 153:1280-1292.

35. Domingues MN, de Souza TA, Cernadas RA, de Oliveira ML, Docena C, Farah CS, Benedetti CE: The Xanthomonas citri effector protein PthA interacts with citrus proteins involved in nuclear transport, protein folding and ubiquitination associated with DNA repair. Mol Plant Pathol 2010, 11:663-675.
36. de Souza TA, Soprano AS, de Lira NP, Quaresma AJ, Pauletti BA, Paes Leme AF, Benedetti CE: The TAL effector PthA4 interacts with nuclear factors involved in RNA-dependent processes including a HMG protein that selectively binds poly(U) RNA. PLoS One 2012, 7:e32305.

37. Domingues MN, Campos BM, de Oliveira ML, de Mello UQ, Benedetti CE: TAL effectors target the C-terminal domain of RNA polymerase II (CTD) by inhibiting the prolyl-isomerase activity of a CTD-associated cyclophilin. PLoS One 2012, 7:e41553.

38. Bennett MJ, Marchant A, Green HG, May ST, Ward SP, Millner PA, Walker AR, Schulz B, Feldmann KA: Arabidopsis AUX1 gene: a permease-like regulator of root gravitropism. Science 1996, 1273:948-950.

39. de Billy F, Grosjean C, May S, Bennett M, Cullimore JV: Expression studies on AUX1-like genes in Medicago truncatula suggest that auxin is required at two steps in early nodule development. Mol Plant Microbe Interact 2001, 14:267-277.

40. Vandenbussche F, Petrásek J, Zádníková P, Hoyerová K, Pesek B, Raz V, Swarup R, Bennett M, Zazímalová E, Benková E, van der Straeten D: The auxin influx carriers AUX1 and LAX3 are involved in auxin-ethylene interactions during apical hook development in Arabidopsis thaliana seedlings. Development 2010, 137:597-606.

41. Dereeper A, Guignon V, Blanc G, Audic S, Buffet S, Chevenet F, Dufayard JF, Guindon S, Lefort V, Lescot M, Claverie JM, Gascuel O: Phylogeny.fr: robust phylogenetic analysis for the non-specialist. Nucleic Acids Res 2008, 36(Web Server issue):W465-W469.

42. Du Z, Zhou X, Ling Y, Zhang Z, Su Z: agriGO: a GO analysis toolkit for the agricultural community. Nucleic Acids Res 2010, 38(Web Server issue):W64-W70.

43. Nishimura R, Ohmori M, Fujita H, Kawaguchi M: A Lotus basic leucine zipper protein with a RING-finger motif negatively regulates the developmental program of nodulation. Proc Natl Acad Sci U S A 2002, 99:15206-15210.

44. Wang H, Jones B, Li Z, Frasse P, Delalande C, Regad F, Chaabouni S, Latché A, Pech JC, Bouzayen M: The tomato Aux/IAA transcription factor IAA9 is involved in fruit development and leaf morphogenesis. Plant Cell 2005, 17:2676-2692.

45. Weller JL, Hecht V, Vander Schoor JK, Davidson SE, Ross JJ: Light regulation of gibberellin biosynthesis in pea is mediated through the COP1/HY5 pathway. Plant Cell 2009, 21:800-813.

46. Zhang Z, Li Q, Li Z, Staswick P, Wang M, Zhu Y, He Z: Dual regulation role of GH3.5 in salicylic acid and auxin signaling during ArabidopsisPseudomonas syringae interaction. Plant Physiol 2007, 145:450-464

47. Zhou J, Tang X, Martin GB: The Pto kinase conferring resistance to tomato bacterial speck disease interacts with proteins that bind a cis-element of pathogenesis-related genes. EMBO J 1997, 16:3207-3218.

48. Doyle EL, Booher NJ, Standage DS, Voytas DF, Brendel VP, Vandyk JK, Bogdanove AJ: TAL Effector-Nucleotide Targeter (TALE-NT) 2.0: tools for TAL effector design and target prediction. Nucleic Acids Res 2012, 40: W117-W122.

49. Nambara $E$, Keith $K$, McCourt $P$, Naito S: A regulatory role for the $A B / 3$ gene in the establishment of embryo maturation in Arabidopsis thaliana. Development 1995, 121:629-636.

50. Nitsch LM, Oplaat C, Feron R, Ma Q, Wolters-Arts M, Hedden P, Mariani C, Vriezen WH: Abscisic acid levels in tomato ovaries are regulated by LeNCED1 and SICYP707A1. Planta 2009, 229:1335-1346.

51. Zeng $Y$, Zhao T, Kermode AR: A conifer ABI3-interacting protein plays important roles during key transitions of the plant life cycle. Plant Physiol 2013, 161:179-195.

52. Noël LD, Denancé N, Szurek B: Predicting promoters targeted by TAL effectors in plant genomes: from dream to reality. Front Plant Sci 2013, 4:333.

53. Tao LZ, Cheung AY, Wu HM: Plant Rac-like GTPases are activated by auxin and mediate auxin-responsive gene expression. Plant Cell 2002, $14: 2745-2760$

54. Sun A, Tawfik O, Gayed B, Thrasher JB, Hoestje S, Li C, Li B: Aberrant expression of SWI/SNF catalytic subunits BRG1/BRM is associated with tumor development and increased invasiveness in prostate cancers. Prostate 2007, 67:203-213.

55. O'Donoghue EM, Somerfield SD, Sinclair BK, Coupe SA: Xyloglucan endotransglycosylase: a role after growth cessation in harvested asparagus. Aust J Plant Physiol 2001, 28:349-361.

56. Husbands A, Bell EM, Shuai B, Smith HM, Springer PS: LATERAL ORGAN BOUNDARIES defines a new family of DNA-binding transcription factors 
and can interact with specific bHLH proteins. Nucleic Acids Res 2007, 35:6663-6671.

57. Fraissinet-Tachet L, Baltz R, Chong J, Kauffmann S, Fritig B, Saindrenan P: Two tobacco genes induced by infection, elicitor and salicylic acid encode glucosyltransferases acting on phenylpropanoids and benzoic acid derivatives, including salicylic acid. FEBS Lett 1998, 437:319-323.

58. Igarashi D, Ishida S, Fukazawa J, Takahashi Y: 14-3-3 proteins regulate intracellular localization of the bZIP transcriptional activator RSG. Plant Cell 2001, 13:2483-2497.

59. Zhang ZT, Zhou Y, Li Y, Shao SQ, Li BY, Shi HY, Li XB: Interactome analysis of the six cotton 14-3-3 s that are preferentially expressed in fibres and involved in cell elongation. J Exp Bot 2010, 61:3331-3344.

60. Moriuchi H, Okamoto C, Nishihama R, Yamashita I, Machida Y, Tanaka N: Nuclear localization and interaction of RolB with plant 14-3-3 proteins correlates with induction of adventitious roots by the oncogene rolB. Plant J 2004, 38:260-275.

61. Vialart G, Hehn A, Olry A, Ito K, Krieger C, Larbat R, Paris C, Shimizu B, Sugimoto Y, Mizutani M, Bourgaud F: A 2-oxoglutarate-dependent dioxygenase from Ruta graveolens L. exhibits p-coumaroyl CoA 2'-hydroxylase activity (C2'H): a missing step in the synthesis of umbelliferone in plants. Plant J 2012, 70:460-470.

62. Itoh H, Tanaka-Ueguchi M, Kawaide H, Chen X, Kamiya Y, Matsuoka M: The gene encoding tobacco gibberellin 3beta-hydroxylase is expressed at the site of GA action during stem elongation and flower organ development. Plant J 1999, 20:15-24.

63. Beyene $\mathrm{G}$, Foyer $\mathrm{CH}$, Kunert KJ: Two new cysteine proteinases with specific expression patterns in mature and senescent tobacco (Nicotiana tabacum L.) leaves. J Exp Bot 2006, 57:1431-1443.

64. Zhang XM, Wang Y, LV XM, Li H, Sun P, Lu H, Li FL: NtCP56, a new cysteine protease in Nicotiana tabacum L., involved in pollen grain development. J Exp Bot 2009, 60:1569-1577.

65. Yang ZN, Ye XR, Molina J, Roose ML, Mirkov TE: Sequence analysis of a 282-kilobase region surrounding the citrus Tristeza virus resistance gene (Ctv) locus in Poncirus trifoliata L. Raf. Plant Physiol 2003, 131:482-492.

66. Pnueli L, Gutfinger T, Hareven D, Ben-Naim O, Ron N, Adir N, Lifschitz E: Tomato SP-interacting proteins define a conserved signaling system that regulates shoot architecture and flowering. Plant Cell 2001, 13:2687-2702.

67. Raíces M, Gargantini PR, Chinchilla D, Crespi M, Téllez-Iñón MT, Ulloa RM: Regulation of CDPK isoforms during tuber development. Plant Mol Biol 2003, 52:1011-1024.

68. Chen Y, Liu Z, Halterman DA: Molecular determinants of resistance activation and suppression by Phytophthora infestans effector IPI-O. PLoS Pathog 2012, 8:e1002595.

69. Radwan O, Mouzeyar S, Nicolas P, Bouzidi MF: Induction of a sunflower CC-NBS-LRR resistance gene analogue during incompatible interaction with Plasmopara halstedii. J Exp Bot 2005, 56:567-575.

70. Durrant WE, Rowland O, Piedras P, Hammond-Kosack KE, Jones JD: CDNA-AFLP reveals a striking overlap in race-specific resistance and wound response gene expression profiles. Plant Cell 2000, 12:963-977.

71. Yordanov YS, Regan S, Busov V: Members of the LATERAL ORGAN BOUNDARIES DOMAIN transcription factor family are involved in the regulation of secondary growth in Populus. Plant Cell 2010, 22:3662-3677.

72. Gao H, Wu X, Chai J, Han Z: Crystal structure of a TALE protein reveals an extended N-terminal DNA binding region. Cell Res 2012, 22:1716-1720.

73. Meckler JF, Bhakta MS, Kim MS, Ovadia R, Habrian CH, Zykovich A, Yu A, Lockwood SH, Morbitzer R, Elsäesser J, Lahaye T, Segal DJ, Baldwin EP: Quantitative analysis of TALE-DNA interactions suggests polarity effects Nucleic Acids Res 2013, 41:4118-4128.

74. Sugio A, Yang B, Zhu T, White FF: Two type III effector genes of Xanthomonas oryzae pv. oryzae control the induction of the host genes OsTFIIAY1 and OsTFX1 during bacterial blight of rice. Proc Natl Acad Sci U S A 2007, 104:10720-10725.

75. Streubel J, Pesce C, Hutin M, Koebnik R, Boch J, Szurek B: Five phylogenetically close rice SWEET genes confer TAL effector-mediated susceptibility to Xanthomonas oryzae pv. oryzae. New Phytol 2013, 200:808-819.

76. Domingo C, Andrés F, Tharreau D, Iglesias DJ, Talón M: Constitutive expression of OsGH3.1 reduces auxin content and enhances defense response and resistance to a fungal pathogen in rice. Mol Plant Microbe Interact 2009, 22:201-210.
77. Navarro L, Dunoyer P, Jay F, Arnold B, Dharmasiri N, Estelle M, Voinnet O, Jones JD: A plant miRNA contributes to antibacterial resistance by repressing auxin signaling. Science 2006, 312:436-439.

78. Wang D, Pajerowska-Mukhtar K, Culler AH, Dong X: Salicylic acid inhibits pathogen growth in plants through repression of the auxin signaling pathway. Curr Biol 2007, 17:1784-1790.

79. Fu J, Liu H, Li Y, Yu H, Li X, Xiao J, Wang S: Manipulating broad-spectrum disease resistance by suppressing pathogen-induced auxin accumulation in rice. Plant Physiol 2011, 155:589-602.

80. Liu H, Wang S, Yu X, Yu J, He X, Zhang S, Shou H, Wu P: ARL1, a LOB-domain protein required for adventitious root formation in rice. Plant J 2005, 43:47-56.

81. Campos BM, Sforça ML, Ambrosio AL, Domingues MN, Brasil de Souza T de A, Barbosa JA, Paes Leme AF, Perez CA, Whittaker SB, Murakami MT, Zeri AC, Benedetti CE: A redox 2-cys mechanism regulates the catalytic activity of divergent cyclophilins. Plant Physiol 2013, 162:1311-1323.

82. Inukai $Y$, Sakamoto T, Ueguchi-Tanaka M, Shibata Y, Gomi K, Umemura I, Hasegawa Y, Ashikari M, Kitano H, Matsuoka M: Crown rootless1, which is essential for crown root formation in rice, is a target of an AUXIN RESPONSE FACTOR in auxin signaling. Plant Cell 2005, 17:1387-1396.

83. Gallego-Giraldo L, García-Martínez JL, Moritz T, López-Díaz I: Flowering in tobacco needs gibberellins but is not promoted by the levels of active GA1 and GA4 in the apical shoot. Plant Cell Physiol 2007, 48:615-625.

84. Nakata M, Yuasa T, Takahashi Y, Ishida S: CDPK1, a calcium-dependent protein kinase, regulates transcriptional activator RSG in response to gibberellins. Plant Signal Behav 2009, 4:372-374.

85. da Silva A, Ferro JA, Reinach FC, Farah CS, Furlan LR, Quaggio RB, MonteiroVitorello CB, Van Sluys MA, Almeida NF, Alves LM, do Amaral AM, Bertolini MC, Camargo LE, Camarotte G, Cannavan F, Cardozo J, Chambergo F, Ciapina LP, Cicarelli RM, Coutinho LL, Cursino-Santos JR, El-Dorry H, Faria JB, Ferreira AJ, Ferreira RC, Ferro MI, Formighieri EF, Franco MC, Greggio CC, Gruber A, et al: Comparison of the genomes of two Xanthomonas pathogens with differing host specificities. Nature 2002, 417:459-463.

86. de Oliveira ML, Lima Silva CC, Abe VY, Costa MG, Cernadas RA, Benedetti CE: Increased resistance against citrus canker mediated by a citrus MAP kinase. Mol Plant Microbe Interact 2013, 26:1190-1199.

87. de Oliveira MLP, Febres VJ, Costa MGC, Moore GA, Otoni WC: Highefficiency Agrobacterium-mediated transformation of citrus via sonication and vacuum infiltration. Plant Cell Rep 2009, 28:387-395.

88. Jefferson RA, Kavanagh TA, Bevan MW: GUS fusions: beta-glucuronidase as a sensitive and versatile gene fusion marker, in higher plants. EMBO J 1987, 6:3901-3907.

89. Altenhoff AM, Dessimoz C: Phylogenetic and functional assessment of orthologs inference projects and methods. PLoS Comput Biol 2009, 5:e1000262.

90. Wolf $\mathrm{Yl}$, Koonin EV: A tight link between orthologs and bidirectional best hits in bacterial and archaeal genomes. Genome Biol Evol 2012, 4:1286-1294.

91. Altschul SF, Gish W, Miller W, Myers EW, Lipman DJ: Basic local alignment search tool. J Mol Biol 1990, 215:403-410.

92. Korhonen J, Martinmäki P, Pizzi C, Rastas P, Ukkonen E: MOODS: fast search for position weight matrix matches in DNA sequences. Bioinformatics 2009, 25:3181-3182.

93. Solovyev W, Shahmuradov IA: PromH: promoters identification using orthologous genomic sequences. Nucleic Acids Res 2003, 31:3540-3545.

94. Blanco E, Messeguer X, Smith TF, Guigó R: Transcription factor map alignment of promoter regions. PLoS Comput Biol 2006, 2:e49.

95. Roy S, Kagda M, Judelson HS: Genome-wide prediction and functional validation of promoter motifs regulating gene expression in spore and infection stages of Phytophthora infestans. PLoS Pathog 2013, 9:e1003182.

96. Shahmuradov IA, Solovyev W, Gammerman AJ: Plant promoter prediction with confidence estimation. Nucleic Acids Res 2005, 33:1069-1076.

doi:10.1186/1471-2164-15-157

Cite this article as: Pereira et al:: Identification of putative TAL effector targets of the citrus canker pathogens shows functional convergence underlying disease development and defense response. BMC Genomics 2014 15:157. 